\title{
Trust-Building Mechanisms in Group-Based Microfinance: A Cameroonian Perspective
}

\author{
Nathanael Ojong \& Amon Simba
}

\begin{abstract}
While trust is critical to microlending groups, much less is known about the vital factors and mechanisms that foster its emergence in microlending groups. This paper examines the practices of trust building and use in microlending groups. The results suggest that trust is produced and developed in microlending groups through a combination of calculative, prediction, intentionality, capability and transference mechanisms. These mechanisms are not mutually exclusive but act together to build trust. Though trust has general characteristics, whether and how it is formed and developed in microlending groups depends on contextspecific factors such as informal debt relations. Trust among group members is bolstered by multiplex relations of social events, neighbourhood, and friendship. The paper suggests that the unbanked population has a rich informal credit history.
\end{abstract}

Keywords: trust, microfinance, informal debt relations, contextual factors, Cameroon

\section{INTRODUCTION}

Microfinance, defined as the provision of loans, savings, insurance, and payment services denominated in small amounts to segments of the population that formerly had no access to formal financial services (Baruah, 2010; Bruton et al., 2015; Guérin \& Kumar, 2017; Servet, 2015; Siwale \& Okoye, 2017), has generated great interest in a number of academic disciplines. Unlike mainstream banking relationships where there are well-designed mechanisms, a high degree of trust is required if microlending groups are to function successfully.

According to transaction cost economics, in a world without transaction costs, all activities would be carried out as exchanges (Gulati, 1995). Notwithstanding this, the act of carrying out 'unregulated' exchanges, synonymous with microlending group activities, has inherent risks. 
Such risks often arise due to the vulnerability of relying on others and the possibility of incurring a loss (Anderson, Steinerte, \& Russell 2010; Nooteboom, 2002). Perhaps, as a way to mitigate this vulnerability of actors engaged in non-collateral microlending group activities, trust can function as a control mechanism (Das \& Teng, 1998). When explaining trust as a control mechanism in organisational groups and teams, Bradach \& Eccles (1989) differentiated trust from control as regulation. Bradach \& Eccles (1989) essentially used the term 'controlling exchanges' to mean the conduct and facilitation of transactions in cooperatives, effectively distinguishing it from the concept of control as regulation in quasi-markets.

It is therefore plausible to claim that trust can function as an effective control mechanism in non-collateral microlending group activities in countries characterised by weak institutions. Members of a microlending group - that operates based on joint liability - must have the assurance that other members will not act opportunistically by leaving the group after securing a loan, passing on the repayment responsibility to other members. In the absence of trust among group members, microlending group activities are likely to fail.

Although extant literature has examined microfinance (Baruah, 2010; Kotir \& ObengOdoom, 2009; Milanov et al., 2015; Sanyal, 2015, Servet, 2015), and trust (Altinay et al., 2014, Lascaux, 2015; van Bastelaer \& Leathers, 2006, Ojong, 2018), much less is known about the mechanisms through which trust is produced among members in microlending groups. More so, the cultural and contextual factors mediating trust-formation among borrowers are implicit in the extant scholarship. This study attempts to fill this lacuna in academic literature.

Specifically, the study provides new insights into how trust is produced, developed and employed in microlending groups in Cameroon. In doing so, it explores the calculative, intentionality, capability, prediction, and transference mechanisms of trust-building in the SubSaharan African country. Crucially, we analyse the moderating effects of cultural dimensions and contextual factors comprising informal financial clubs and informal debt relationship using 
the above-mentioned mechanisms. We address the following key question: how is trust formed and developed in a microlending group?

This study offers two primary contributions. First, we investigate how trust is produced and developed in microlending groups. We strictly utilise Doney et al's (1998) framework comprising calculative, prediction, intentionality, capability, and transference trust-building mechanisms. Clearly, our contribution here is the interface between trust and microfinance. Second, the novelty of our study lies in the Cameroonian context we utilise. We draw attention to contextual influences (Elsner \& Schwardt, 2015; Smallbone et al., 2014, Welter, 2012) in the country. Thus, we contribute to mainstream theories by exploring a non-mainstream context and acknowledging 'the different contexts' in which trust occurs (Welter, 2012, p. 193).

In the literature review that follows, we analyse microfinance and the group-based lending model, including the five mechanisms, highlighted above, through which trust can be produced and developed. The literature identifies that trust is indeed important for microlending group activities. Yet there is a research gap in our knowledge about how trust is produced and developed in microlending groups. In the next sections, we outline the research methodology and examine practices of trust building and use in microlending groups. We conclude by discussing the practical implications of the study findings.

\section{BACKGROUND LITERATURE}

\subsection{The Provision of Microfinance}

Microfinance provision has attracted mainstream banks, investment funds, not-for-profit actors, insurance companies, mobile network operators (Bruton et al., 2015), and, more recently, internet-based crowdfunding intermediaries (Allison et al., 2015).

The group-based lending model is often used in environments with weak institutions and no formal collateral to secure loans (Carli \& Uras, 2017; Milanov et al., 2015). Group lending 
purports to transfer the screening, monitoring, and enforcement of loans to the collective of borrowers (Carli \& Uras, 2017). The underlying logic behind the group lending model is that individuals within a group can be considered not eligible to get microloans but the group, as a whole, is creditworthy (Baland, Rohini \& Zaki, 2014; Haldar \& Stiglitz, 2016). Two strains of theorizing account for why group lending has proven so effective in encouraging high repayment rates: the borrower's social ties and the idea that the group replaces conventional collateral with social collateral (Haldar \& Stiglitz, 2016). Joint liability, that is 'making borrowers liable for each other's repayments in case of credit default' is a major feature of group loan contracts (Carli \& Uras, 2017, p. 72). In recent years, MFIs have begun using the group lending model without the joint liability clause which means that borrowers are no longer liable for each other's loan repayments in case of default (Baland, Rohini \& Zaki, 2014). In fact, group lending without joint liability has been successful due to the role of reputation (ibid). Clearly, borrowers using the joint liability group lending model are exposed to considerable risk. The inherent risk in such microlending groups highlights the importance of trust. Risk is required for trust to influence choice and behaviour (Lewis \& Weigert 1985).

\subsection{Trust Formation and Microfinance}

Though scholars differ on the conceptualization of trust, there is however a consensus on some of its principal elements. For the sake of brevity and to allow us to move quickly to discuss the interface between trust and microfinance, we draw on previous work regarding the general nature of trust (see Ojong, 2018, p. 21-22).

Particularly significant to this discussion is the work by Doney \& Cannon (1997) and Doney et al. (1998), which identifies five cognitive trust-building mechanisms: calculative, prediction, intentionality, capability, and transference. The authors note that the mechanisms trustors use to build trust may depend to a great degree on culture. Indeed, Hofstede (1980) indicates that trust is connected to broader cultural norms. 
Though trust may form through calculative, prediction, intentionality, capability, and transference mechanisms, whether and how it is formed depends on the societal values and norms that guide people's behaviour and beliefs (Doney et al., 1998). Therefore, Hofstede (1980) identifies culture dimensions that influence trust-building mechanisms: individualism/collectivism, masculinity/femininity, high/low power distance, high/low uncertainty avoidance. According to the calculative mechanism, the trustor calculates the costs and rewards of a target cheating (Lindskold, 1978). Incentives and a rational assessment of rewards and punishments are the central tenets underlying calculative-based trust (Poppo, et al., 2016). Doney et al. (1998) contend that individualism/collectivism, masculinity/femininity, high power distance, and low uncertainty avoidance dimensions influence the likelihood that people will act opportunistically. For instance, the probability that collectivists will act opportunistically is low as people hold group values and pursue collective interests (Hofstede, 1984). Because of the collectivist culture, deterrence mechanisms, such as social sanctions, curb opportunistic behaviour by increasing the costs of cheating (Doney et al., 1998).

In the context of group-based microfinance, group members (in collectivist societies) would not act opportunistically since the costs of opportunistic behaviour (social sanctions) are high and outweigh the benefits of cheating. Similarly, members of microlending groups face high cost for acting opportunistically in feminine societies since people hold solidarity and cooperative norms and abhor self-serving behaviour. On the other hand, 'tough' values in masculine societies, such as assertiveness, visible achievement, and making money (Hofstede, 1984), indicate that the potential benefits for acting opportunistically may exceed the costs (Doney et al., 1998).

Regarding power distance, Doney et al. (1998) contend that people in low power distance cultures are less likely to act opportunistically since such societies tend to adopt a participative decision-making process and hold norms of interdependence and solidarity, which is contrary 
to high power distance cultures. On this premise, the authors argue that trustors in high power distance cultures are more likely to build trust via a calculative process. The level of risk tolerance in societies influences the assessments required for calculative trust formation (Lewicki \& Bunker, 1996). Arguably, the fact that people in high uncertainty avoidance cultures display a strong resistance to change (Kale \& Barnes, 1992) suggests that people are not likely to act opportunistically as doing so endangers continuation of the relationship (Doney et al., 1998). Therefore, people in low uncertainty avoidance cultures are more likely to build trust through a calculative mechanism (Doney et al., 1998).

Trust based on prediction relies on a trustor's ability to forecast the target's behaviour (Rempel \& Holmes, 1986). In the context of microfinance, prediction denotes an MFI's ability to forecast that borrowers will be able to repay their loans (Aggarwal et al., 2015). Similarly, for joint liability microlending groups, members would only select people whom they are able to forecast their loan repayment ability. Put simply, group members should be able to forecast the repayment ability of one another. Servet (1997) notes that trust develops from expectations of how a person will act or behave based on that person's past behaviour and their explicit and implicit claims. Trust then emerges from a prediction process whereby a partner determines that another's past actions provide a reasonable basis upon which to predict their future behaviour with accuracy (Doney et al., 1998). The behaviour and past actions of another partner requires information gathering across multiple interactions (Lewicki \& Bunker, 1996). Memory, then, is a key ingredient since it enables a partner to compare past actions and behaviour of the other partner (Servet, 1997).

Doney et al. (1998) suggest that under the cultural dimensions of collectivism, femininity, low power distance, and high uncertainty avoidance, trustors are more likely to form trust through a prediction mechanism. This follows from the fact that norms such as self-orientation, low loyalty to other people, and freedom to act individually, for example, run counter to a 
predictable behaviour (Doney et al., 1998). Additionally, it is more difficult to predict with accuracy the behaviour of people who hold individualist values as the costs of opportunistic behaviour are low (since violators cannot be ostracised by a group) (Doney et al., 1998).

Trust emerges through an intentionality mechanism wherein one party interprets another party's words and behaviour and tries to determine their intentions (Lindskold, 1978). From a microfinance perspective, forming trust through intentionality involves ascertaining the motivation and intention of borrowers to repay loans (Aggarwal et al., 2015). Doney et al. (1998) suggest that under cultural dimensions of collectivism, femininity, low power distance, and high uncertainty avoidance, trustors are likely to build trust through an intentionality mechanism.

The capability mechanism of trust building emerges from a trustor's willingness to trust based on an evaluation of the target's ability to meet their obligations as well as the trustor's expectations (Doney et al., 1998). In the context of microfinance, trust formation through the capability mechanism involves an MFI's willingness to trust based on an assessment of borrowers' ability to repay loans (Aggarwal et al., 2015). Doney et al. (1998) suggest that in environments of individualism, masculinity, high power distance, and high uncertainty avoidance trust is more likely to form through a capability mechanism.

Finally, trust may emerge through a transference mechanism wherein trust is transferred from a known entity to an unknown one (Doney et al., 1998). Arguably, one may consider this transference process of trust formation as using a 'third party's definition of another as a basis for defining that other as trustworthy' (Strub \& Priest, 1976, p. 399). Seen in this light, trust is transferred from a trusted 'proof source'-for example, from someone with good reputation and certification (Rousseau et al., 1998) — to another person. These proof sources enable the verification of the party's trustworthiness and links known parties and unknown ones (Doney et al., 1998). Therefore, in order to establish trust through a transference process, trustors must 
be able to identify proof sources and these sources must be perceived as being trustworthy (Doney et al., 1998). Doney et al. (1998) suggest that under Hofstede's cultural dimensions of collectivism, femininity, low power distance, and high uncertainty avoidance trust is more likely to be formed through the transference mechanism. In the context of microfinance, trust is transferred from a trusted source, such as an individual or institution, to a borrower. This means that if trust is to be formed in microlending groups through the transference process, potential members of the group must identify a trustworthy source that serves as a proof source.

While some scholars (e.g., Aggarwal et al., 2015; Augustine, 2012; Dowla, 2006; Panda, 2016; Sriram, 2005; van Bastelaer \& Leathers, 2006; Ojong, 2018) have acknowledged the importance of trust in microfinance operations (Table 1), little attention has been directed to understanding practices of trust building and use in microlending groups. Aggarwal et al. (2015) briefly touched on trust formation in the microfinance domain but did not analyse how trust is produced, developed and employed since the focus of their study was to examine how MFIs target women borrowers to deal with low social trust. A recent study examined the role played by traditional leaders in the calculative and transference processes of trust building between MFIs and borrowers (Ojong, 2018). However, the study did not examine trust building among borrowers in microlending groups. This paper expands upon that study, including those of other scholars, by investigating practices of trust building and use in microlending groups, including how trust formation is mediated by contextual factors such as informal financial clubs and informal debt relations. ${ }^{1}$

\footnotetext{
${ }^{1}$ By informal financial clubs we refer to rotating savings and credit associations (RoSCAs) and accumulating saving and credit associations (ASCAs). RoSCAs are 'associations in which members regularly contribute to a fund that is given in whole or in part to each contributor in turn' (Ardener, 2010, p. 11). ASCAs differ from RoSCAs in that the association distributes part of its fund as loans to members, and members get their share of the fund at the end of the cycle.
} 
Table 1: Summary of Literature at the Interface Between Trust and Microfinance

\begin{tabular}{|c|c|c|}
\hline Authors & Type & Summary \\
\hline Sriram (2005) & Conceptual & $\begin{array}{l}\text { Repeated transactions } \\
\text { build up institutional } \\
\text { memory, paving the way } \\
\text { for organizational trust } \\
\text { to possibly replace } \\
\text { interpersonal trust. }\end{array}$ \\
\hline Aggarwal et al. (2015) & Empirical & $\begin{array}{l}\text { Microfinance institutions } \\
\text { target women borrowers } \\
\text { as a substitute for and to } \\
\text { deal with low social } \\
\text { trust. }\end{array}$ \\
\hline van Bastelaer and Leathers (2006) & Empirical & $\begin{array}{l}\text { Trust is strongly } \\
\text { associated with } \\
\text { repayment performance. }\end{array}$ \\
\hline Augustine (2012) & Empirical & $\begin{array}{l}\text { Transparency in all } \\
\text { aspects of a } \\
\text { microfinance } \\
\text { institution's operations } \\
\text { creates trust with all its } \\
\text { stakeholders. }\end{array}$ \\
\hline Dowla (2006) & Conceptual & $\begin{array}{l}\text { Borrowers tend to trust } \\
\text { microfinance institutions } \\
\text { that trust them too. }\end{array}$ \\
\hline Panda (2016) & Empirical & $\begin{array}{l}\text { Group formation based } \\
\text { on peer trust. }\end{array}$ \\
\hline Ojong (2018) & Empirical & $\begin{array}{l}\text { Traditional leaders } \\
\text { facilitate trust building } \\
\text { between microfinance } \\
\text { institutions and their } \\
\text { borrowers. }\end{array}$ \\
\hline
\end{tabular}




\section{METHODOLOGY}

\subsection{The Context}

Given our approach, it is essential to describe our context (Pratt, 2009). Regarding cultural dimensions (Hofstede, 1984), Cameroon is a masculine and high-power distance country (Researchomatic, 2012). Also, it is a collectivist society though there is the emergence of individualism (Pirttilä-Backman et al., 2004). The emergence of individualism, especially in the urban areas, is attributed to people 'getting more absorbed into the Western-dominated, global, free-market economies that emphasize the ideology of individualism' (Mpofu 1994 cited in Pirttilä-Backman et al., 2004, p. 495). Others contend that urbanization, socioeconomic crises, and education have contributed to the emergence of individualism (Marie, 1997). The predominantly collectivist state of most communities explains why trust is built through certain trust-building mechanisms.

This study focused on clients of an MFI that uses the group-based lending model. This MFI operates in Mezam and Boyo, administrative divisions that are situated in the North-West Region of Cameroon. Boyo is primarily a rural area, while Mezam is comprised of both urban and rural areas. Established in 1998, this MFI has a history of providing loans to the low-income population.

Borrowers form groups made up of five persons. Group members must be of the same gender and age range, and they cannot be family members.

\subsection{Methods Adopted}

A qualitative lens was adopted to examine practices of trust building and use in microlending groups. Such an approach can support development of a better understanding of a topic of interest (Denzin \& Lincoln, 2011). The approach was appropriate because our objective was in 
addressing the 'how' (than 'how many') and 'articulating processes' (Pratt, 2009, p. 856) of trust building in microlending groups.

\section{(i) Sampling}

The principal methodological strategy in selecting respondents at the outset was to have sufficient variety. To this end, we selected respondents from Mezam and Boyo, as they are regions that capture the rural-urban dynamics, which are vital to our study regarding practices of trust building and use. Respondents had various characteristics (Table 2).

Table 2: Characteristics of Respondents

\begin{tabular}{|c|c|c|}
\hline \multicolumn{2}{|c|}{ Characteristic } & Percentage \\
\hline \multirow[b]{2}{*}{ Gender } & Male & $58.7 \%$ \\
\hline & Female & $41.3 \%$ \\
\hline \multirow{4}{*}{$\begin{array}{c}\text { Marital } \\
\text { Status }\end{array}$} & Single & $4.3 \%$ \\
\hline & Married & $80.4 \%$ \\
\hline & Divorced & $2.3 \%$ \\
\hline & Widow & $13 \%$ \\
\hline \multirow{4}{*}{ Age } & $20<35$ & $15.2 \%$ \\
\hline & $35<45$ & $24 \%$ \\
\hline & $45<55$ & $34.8 \%$ \\
\hline & 55> & $26 \%$ \\
\hline
\end{tabular}




\begin{tabular}{|c|c|c|}
\hline \multirow{4}{*}{\begin{tabular}{c|c|}
$*$ \\
\multirow{3}{*}{$\begin{array}{c}\text { Level of } \\
\text { education }\end{array}$}
\end{tabular}} & Primary & $71.7 \%$ \\
\cline { 2 - 3 } & Secondary & $19.6 \%$ \\
\cline { 2 - 3 } & University & $2.2 \%$ \\
\cline { 2 - 3 } & No formal education & $6.5 \%$ \\
\hline
\end{tabular}

Source: Based on authors' fieldwork, 2011

We selected an MFI that uses the group-based lending model since their clients would provide experiences appropriate for the study. This MFI, due to its group-based lending model, seemed to offer an ideal environment to study trust formation in groups. The MFI has centres made up of several groups. From each group, we selected respondents who had obtained a loan and were willing to have an interview (usually at least half of the group). The same process was done in both rural and urban zones to capture diversity.

\section{(ii) Data collection}

One author's established relationship with the management of this MFI facilitated research access to their borrowers and employees. The author attended group meetings in the presence of loan officers.

\section{(iii) Interviews}

Our qualitative approach is endowed with its own criteria of rigour, including contextualisation and saturation (Guérin \& Kumar, 2017). A total of 51 face-to-face semi-structured interviews with clients (46) and employees (five) of the MFI were completed. Interviewing MFI employees also made it possible to corroborate the narratives of the borrowers. Some follow-up telephone interviews were conducted to get additional information on issues that were missed during the first interviews (Taylor, 1984). To facilitate the disclosure of information, it was made clear to respondents that the information they provided would not be passed on to any third party and 
would be anonymised. Selected respondents were proficient in English and/or Pidgin (the most commonly spoken local language). A translator was not needed as one of the study's authors, who conducted the interviews, is also proficient in Pidgin.

Some interviews were conducted independently in private areas at the branch offices of the MFI (ensuring there was no monitoring by MFI staff in order not to influence responses). Other interviews were conducted at respondents' homes and places of business.

\section{(iv) Analysis technique}

Data collected was sorted before analysis could begin. The sorting process meant interviews conducted in Pidgin were translated into English by one of the authors and all interviews were transcribed. Interviews were read several times and emerging concepts were grouped into categories using open coding (Corbin \& Strauss, 2008) to develop first-order concepts. Firstorder concepts were subsequently categorized into second-order themes (Corley \& Gioia 2004; Pratt, 2009). NVivo 8.0 assisted our analysis.

\section{TRUST-BUILDING MECHANISMS IN MICROLENDING GROUPS}

As noted earlier in this discussion, potential clients of the MFI are required to form groups in order to get loans. Trust underpins the proper functioning of groups and is of vital importance especially in this local context characterised by institutional deficiencies. How, then, are trusting relationships produced, developed and employed in microlending groups?

\subsection{Factors that Influence Trust Building in Microlending Groups}

Contextual factors, such as informal debt relationships, are crucial to trust formation. For a start, groups are formed by individuals who are acquainted with the actions and behaviour of one another. Usually, potential members of a group have the opportunity to take part in social events (such as marriage, birth, and funeral ceremonies) and engage in several interactions with other 
members of informal financial clubs, while those in similar trades engage with their peers on a frequent basis. Spatial proximity with other potential members, therefore, is a key factor.

\section{(i) Role of spatial proximity in trust building}

Spatial proximity makes it possible for people to attend similar social events. Additionally, it facilitates interactions among people in a particular community. Spatial proximity (Servet, 1997) is vital to the intentionality and prediction processes of trust-building between potential members of a microlending group. The role of spatial proximity explains why a respondent said that 'if I reside with a person in the same community, I will know about the person's behaviour. I will know whether the person is troublesome' (Interview 44). Spatial proximity enables frequent interactions and information gathering which makes it possible for people to predict future loan repayment behaviour of other potential members:

$[\mathrm{N}]$ ormally, in life, when one deals with people, one knows those who are truthful and those who are not. Interactions enable one to gather information about a person, so you know the person you are dealing with. Also, in our African communities, we know people's background and attitude because these are small communities (Interview 39).

Given the frequent personal interactions, the prediction and intentionality mechanisms of trust building stand out in the formation of a microlending group as individuals have ample opportunity to examine the consistency of the past actions of others (which, as Doney et al. [1998] note, indicates future behaviour). From this perspective, a respondent said, '[s]ocial events make it possible to know who is who' (Interview 45); another said, '[r]egarding social events, if that person [potential group member] does not associate with others, then, usually, such a person will not be able to establish social relations with others in the group' (Interview 42). A person who is not willing to participate in social events, as indicated by the respondent, displays individualistic traits which run contrary to the cultural dimension of collectivism. The individualist cannot be part of a microlending group because others cannot effectively assess 
their motivation and intentions. This supports the point made by Doney et al. (1998) that, under the cultural dimension of individualism, trustors are unlikely to build trust through an intentionality mechanism.

Trust building through the intentionality process, in this context, requires potential members of a microlending group to know the motivation and intention of others regarding loan repayment (Aggarwal et al., 2015) before the formation of the group as noted by a respondent: '[w] choose those to be in the group. I had to be examined by the other members; then a decision was reached in favour of being part of the group. I have not had problems since being with them. No person causes a problem in the group' (Interview 10). Again, spatial proximity facilitates shared visits and face-to-face interactions, which make it possible to know the motivation and intention of others by interpreting their words and behaviour. Information and experience allow parties to evaluate trustworthiness (Nooteboom, 2002; Servet, 1997), and this knowledge and experience gained during interactions make it possible for trust 'to take root' (Coriat \& Guennif, 1998, p. 54). Informal conversations and frequent interactions make it possible to judge a potential group member's attitude. While acknowledging that trust may also precede experience (Welter, 2012), arguably, 'a trust-based relationship will only survive if it is supported by experience' Coriat \& Guennif (1998, p. 54).

\section{(ii) Informal debt relations as key ingredients in trust building in microlending groups}

Informal loans from neighbours and the purchase of goods on credit from local shopkeepers are vital to the intentionality and prediction mechanisms of trust building. For example, people often get loan requests from neighbours to meet household needs as expressed by a respondent: 'when I have challenges, for instance, when my wife is sick, I explain the situation to my neighbour. So, he lends me money, and I repay when I have money' (Interview 15). By repaying the loans, borrowers send a signal that they are trustworthy. Trustworthiness is a key requirement for those who seek to join a microlending group — even before the formation of a 
group, people in a community have information regarding potential members. Elsner \& Schwardt (2015) contend that trustworthiness depends on people going against short-run gains. However, according to our study, some urban residents go for short-run gains since the benefits of cheating outweigh the costs. This was particularly predominant among the 20-35 age group. Several factors account for this behaviour. First, people in this age bracket tend to be more individualistic. Second, people in this age group were single, which further facilitated their movement from one region to another. Once they act opportunistically in a particular area, they relocate to another region where they are unknown to people in that community. A respondent said, 'I have friends who followed my footsteps and took a loan, some of them have relocated because they weren't able to repay the loan' (Interview 31).

Additionally, people approached shopkeepers in the local community for groceries on credit. This practice was pervasive in our study. A respondent said, 'as we are in the community, if a guest arrives without prior notice, I go to the provision store owned by my neighbour and say, please, I wish to purchase four bottles of beer and two bars of Savon on credit; then I pay back for the goods later' (Interview 27). These informal transactions create debt relationships between people in these communities. Debt relationships enable people to know individuals who are trustworthy.

Honesty and reliability were indicated by respondents as vital to trust building: 'the secret [in a debt relationship] is to be honest. If I purchase groceries on credit from a friend's provision store, I make sure that payment is made immediately when I have it [money], even if I'm left with nothing' (Interview 30). Honesty and reliability constitute some of the key characteristics of a trustworthy partner (Altinay, Saunders, \& Wang. 2014; Nooteboom, 2002). People who pay for groceries purchased on credit or repay a loan owed to a neighbour build up their 'credit history'. In this way, informal debt relationships in local communities enhance a person's credit history. Therefore, this type of information gathered facilitates trust building through the 
intentionality and prediction mechanisms. By failing to repay money owed to a neighbour or a shopkeeper (indicative of past repayment performance), potential members of a microlending group can forecast that the loan defaulters would likely default on a loan provided by an MFI if they are allowed to join a microlending group. Therefore, informal debt relationships in local communities also enable people to know the intention and motivation of potential microlending group members. This suggests that informal debt relationship plays an intermediary role in trust formation.

(iii) Role of Informal financial clubs in trust building

Informal financial clubs are vital to several mechanisms of trust formation. In our study, $91.3 \%$ of respondents were members of at least one informal financial club. In addition to meeting the financial needs of its members, these informal financial clubs serve as platforms to socialize: 'one must belong to a njangi [Informal financial club] because, after everything, one must socialize' (Interview 1). ${ }^{2}$ Members of informal financial clubs meet on a regular basis: weekly, fortnightly, and monthly. The frequent meetings and numerous interactions facilitate the gathering of information.

Information gathered through multiple interactions between members of these clubs make it possible to forecast a person's behaviour and benevolent intentions as well as to determine the reliability and dependability of a potential microlending group member. For example, members of an informal financial club who act opportunistically by defaulting on a loan send a signal to other members about their motivation should they join a microlending group with the aim of obtaining a loan from an MFI. Thus, trust arises from the recommendations of members within the group (Williamson, 1993). Trust also relies on reputation-information possessed by individuals about a potential member of a microlending group regarding their behaviour in prior

\footnotetext{
${ }^{2}$ An informal financial club is locally referred to as njangi and tontine in Anglophone and Francophone Cameroon respectively.
} 
network or group relations (Welter \& Smallbone, 2006). Accordingly, reliability and dependability in previous interactions and experiences (Rousseau et al., 1998) generate positive expectations about the motivation and intention of a potential microlending group member regarding repayment of loans that will be granted by the MFI.

Trust formation by means of the transference mechanism involves the transfer of trust from a known party to an unknown party (Doney et al., 1998). A respondent describes this process in the microfinance context: 'I was a member of a njangi [informal financial club]. The main reason why I joined it was to bring the members here [MFI]. At least ten of them have registered' (Interview 46). The reason why other microlending members accept the new members and the MFI registers them is because they know the existing client and are aware of their past positive loan repayment experience. Trust of the existing client (proof source) leads to other registered clients. Doney et al. (1998) note that transference-based trust assumes that persons that act as a proof source are themselves trustworthy. Of course, this transference process is made possible due to the collectivist and high uncertainty avoidance culture of rural regions. Tight integration in a collectivist culture (Kale \& Barnes, 1992) is contrary to a loosely knit social framework in an individualist culture (Ueno \& Sekaran, 1992). Therefore, this tight integration facilitates the transfer of trust from an existing member (trusted proof source) to an unknown person. Table 3 displays examples regarding the various trust-building mechanisms. 
Table 3: Trust-building Processes and Corresponding Constructs

\begin{tabular}{|c|c|}
\hline Trust-building mechanism & Constructs based on interviews \\
\hline $\begin{array}{l}\text { Calculative: Trustor is aware of the costs } \\
\text { and/or rewards of a target acting } \\
\text { opportunistically (Doney \& Cannon, } \\
\text { 1997; Doney et al., 1998) }\end{array}$ & $\begin{array}{l}\text { - "The [loan] defaulter will be isolated in that } \\
\text { community. They will not be able to join } \\
\text { other groups." }\end{array}$ \\
\hline $\begin{array}{l}\text { Prediction: Trustor develops confidence } \\
\text { that target's behaviour can be predicted } \\
\text { (Doney \& Cannon, 1997; Doney et al., } \\
\text { 1998) }\end{array}$ & $\begin{array}{l}\text { - A starting point is to find out whether the } \\
\text { potential member was once a member of a } \\
\text { group. If the person was a member of a } \\
\text { group, then we find out if the person had } \\
\text { defaulted on a loan. If the person had } \\
\text { defaulted once or twice, then we can forecast } \\
\text { that the person is likely to default." } \\
\text { "If a person often quarrels with their spouse, } \\
\text { we know that such a person will cause } \\
\text { problems in the group." }\end{array}$ \\
\hline $\begin{array}{l}\text { Capability: Trustor assesses the target's } \\
\text { ability to fulfil its promises (Doney \& } \\
\text { Cannon, 1997; Doney et al., 1998) }\end{array}$ & $\begin{array}{l}\text { - "First, the person has to be evaluated to find } \\
\text { out if that person is the sort of person that } \\
\text { will always fail the group. Second, the person } \\
\text { should be hardworking." } \\
\text { - "The person [potential member] should have } \\
\text { an income generating activity. For example, } \\
\text { farming, animal husbandry, petty trading." } \\
\text { - "We know about people's income generating } \\
\text { activities. We know those who are } \\
\text { hardworking and those who are lazy. A lazy } \\
\text { person cannot join [a group]." }\end{array}$ \\
\hline $\begin{array}{l}\text { Intentionality: Trustor evaluates the } \\
\text { target's motivations (Doney \& Cannon } \\
\text { 1997; Doney et al., 1998) }\end{array}$ & $\begin{array}{l}\text { - "Since they [group members] live in the same } \\
\text { community, they know the motivation of } \\
\text { those in the community. They would admit a } \\
\text { person to the group when they determine that } \\
\text { the person will repay loans." } \\
\text { "Interactions enable one to gather } \\
\text { information about a person, so you know the } \\
\text { person you are dealing with." }\end{array}$ \\
\hline $\begin{array}{l}\text { Transference: Trustor draws on 'proof } \\
\text { sources,' from which trust is transferred } \\
\text { to the target (Doney \& Cannon, 1997; } \\
\text { Doney et al., 1998) }\end{array}$ & $\begin{array}{l}\text {-One of the members may bring a person } \\
\text { [potential member] to us since only a member } \\
\text { can bring another person. We would have a } \\
\text { discussion with the member who brought the } \\
\text { person to find out whether the potential } \\
\text { member possesses the characteristics we seek } \\
\text { in order to join the group." }\end{array}$ \\
\hline
\end{tabular}


(iv) Capability and calculative mechanisms of trust building in microlending groups

Once a group is formed, developing trust is crucial to its success. Within a microlending group, members who get their loans later in the loan disbursement cycle expect that members who get theirs early in the loan disbursement cycle will honour their loan repayment commitments so that they too can get their loans. Arguably, trust is produced and developed through the capability mechanism whereby members of a group ensure that each member has the ability to repay loans (Aggarwal et al., 2015). Based on the capability mechanism, group members ensure that members are given a loan amount that they can repay. Asked whether they were given the loan amount requested, a respondent said, '[y]es, for some of us; I was given the 100,000CFA Franc [US\$173] I asked. I believe that they look at your ability because several people ask and it [loan amount requested] isn't given to them' (Interview 15). Another respondent said that 'a person may request 500,000CFA Franc [US\$865] but will be given 50,000CFA Franc [US $\$ 86$ ]. They know that 50,000CFA Franc[US\$86] is sufficient for that person' (Interview 23).

Group members are instrumental in determining the loan repayment ability of an individual in a group due to information asymmetry between the MFI and borrowers. On this point, a respondent noted that 'a person may request a certain amount, but that person will not be given that amount $[\ldots]$ group members would refuse that such an amount should be given to the person because they might not be able to manage the amount' (Interview 1). The fact that the MFI considers the group's recommendation suggests a transference process whereby the MFI trust the group (proof source) regarding an individual's ability, and that trust is then transferred to the group member, who is unknown to the MFI. In this context, the capability and transference mechanisms are intertwined.

Members of a microlending group have various tools to facilitate an assessment of a member's ability. For instance, the assessment of a group member's ability to repay a loan provided by the MFI is also based on their past loan repayment performance in the community 
and as a member of the informal financial club. Therefore, past loan repayment performance ('ability') helps others trust an individual in their group.

Regarding the calculative process, because of the high-power distance (Researchomatic, 2012) and more collectivism than individualism in most communities in the country (PirttiläBackman et al., 2004), particularly in the rural areas, the costs of opportunistic behaviour are quite significant. For example, a member who cheats will not be allowed to join another group as information rapidly disseminates throughout their community. A respondent explained some of the consequences of opportunistic behaviours:

It would be difficult for a credit defaulter to join another group because news will spread that a member joined a group and failed to repay their loan. So, it tarnishes their image and makes it difficult for them to join another group except if they move to another community where they are unknown (Interview 44).

The sanctions imposed on a member who acts opportunistically corroborates the point made by Welter (2012) that personal trust is often accompanied by sanctions (i.e., control mechanisms). At the micro-level, in our context, these social sanctions can include, for example, a loss of reputation for the person who acts cheats.

Additionally, as most members of a microlending group are also members of informal financial clubs, an opportunistic behaviour would affect one's relationship in the club. Informal financial clubs, in our context, are very attractive for numerous reasons:

In the njangi [informal financial club], we have a sinking fund. When there is a sad event, we withdraw money from it and assist a member. For example, we can withdraw 50,000 CFA Franc [US\$81.85] from that fund [...]. Examples of sad events include the loss of a parent, sibling or child, accidents, and sickness. In the case of a sad event, members would be physically present and express sympathy [...] A member can say that 'I am sick and cannot buy drugs,' members can assist that person. For example, each member might contribute 1000 CFA Franc [US\$1.63], or they can lend the person the money required at a lower interest rate [...] Njangi is about solidarity; people want to share [...] people share information 
regarding job opportunities and other opportunities they are aware of. They can also give members priority in terms of getting those job opportunities (Interview 43).

The extensive benefits of being part of a social network means that a person would pay a relatively high price for an opportunistic behaviour. However, it is worth noting that the threat of sanctions does not dissuade some urban residents from acting opportunistically by defaulting on a loan repayment. In our study, microlending groups in urban areas recorded several cases where members deliberately decided to default on a loan repayment. The high loan delinquency rate in the urban zones is due to some of the factors mentioned earlier. Higher levels of individualism (when compared with rural zones) and cultural heterogeneity are other crucial factors that account for opportunistic behaviour. Unlike a previous study that showed Kenyan women are more responsive to social pressure — due to shame and embarrassment — than men (Johnson, 2005), our study found that urban women in microlending groups are not so responsive to social pressure.

\section{CONCLUSION}

This article contributes to the literature at the interface between trust and microfinance. The study helps fill gaps in the literature by investigating the practices of trust building and use in microlending groups. Our findings regarding the importance of culture to trust-building are consistent with extant scholarship (Doney et al., 1998; Altinay et al., 2014). Unlike the previous studies, however, this research suggests that contextual factors, such as informal financial clubs, purchase of goods on credit from local shopkeepers, and other informal debt relationships mediate trust formation in microlending groups. This means there is a contextual sensitivity of trust building. Arguably, these contextual factors indicate habituation is crucial to trust development. Also, though trust has general characteristics, context-specific factors and mechanisms mediate its emergence. For instance, Doney et al. (1998) contend that trust is likely to form through the prediction and intentionality mechanisms in feminine societies. Our 
findings suggest that trust can also develop through the prediction and intentionality mechanisms in masculine societies. We argue that some contextual factors facilitate trust development in masculine societies. Additionally, the establishment of debt relationships between individuals in communities facilitate the building of an individual's 'credit history'. The credit history provides rich information to tackle the problem of information asymmetry. This information enables microlending group members to determine the capability (ability) of other individuals to pay back loans. This information is transferred to the MFI that makes a final decision — on the basis of information received from the group (proof source) — regarding the loan amount to give an individual in a group. So, the capability and transference mechanisms are not mutually exclusive but are intimately intertwined.

Our findings have important practical implications for MFIs. In showing practices of trust building and use, we make apparent the mechanisms available to MFIs in low-income economies with weak institutions. MFIs could design mechanisms that enable them to make use of informal credit histories of potential borrowers. Perhaps doing so may help to reduce the risk of delivering formal financial services to low-income individuals with no formal credit history. Also, some cultural norms held by people shift even when they move within national boundaries. This explains why when some people move from rural communities, which tend to be collectivist, to urban areas, which are increasingly individualistic, they gradually become more individualistic. Therefore, an MFI should not assume that the same trust mechanisms that work in rural areas will work in urban areas. Trust must be analyzed through the eyes of each particular community. Taking into consideration contextual factors is crucial as it would avoid inappropriate transfer of so-called 'best practices.'

\section{REFERENCES}

Aggarwal, R.., Goodell, J., \& Selleck, L. (2015). Lending to women in microfinance: Role of social trust. International Business Review, 24, 55-65. 
Allison, T., Davis, B., Short, J., \& Webb, J. (2015). Crowdfunding in a Prosocial Microlending Environment: Examining the Role of Intrinsic Versus Extrinsic Cues. Entrepreneurship Theory \& Practice, 39(1), 53-73.

Altinay, L., Saunders, M., \& Wang, C. (2014). The Influence of Culture on Trust Judgments in Customer Relationship Development by Ethnic Minority Small Businesses. Journal of Small Business Management, 52(1), 59-78.

Anderson, A., Steinerte, E., \& Russell. E. (2010). The nature of trust in virtual entrepreneurial networks. International Journal of Entrepreneurship and Innovation, 1(1), 1-21.

Ardener, S. (2010). Microcredit, Money Transfers, Women, and the Cameroon Diaspora. Africa Focus, 23(2), 11 -24.

Augustine, D. (2012). Good Practice in Corporate Governance: Transparency, Trust, and Performance in the Microfinance Industry. Business \& Society, 51(4), 659-676.

Baland, J-M., Rohini, S., \& Zaki, W. (2014). Group lending and endogenous social sanctions, School of Economics Discussion Papers, No. 1415.

Baruah, B. (2010). NGOs in Microfinance: Learning from the Past, Accepting Limitations, and Moving Forward. Geography Compass, 2(6), 1-14.

Bradach, J., \& Eccles, R. (1989). Price, authority, and trust: From ideal types to plural forms. Annual Review of Sociology, 15, 97-118.

Bruton, G., Khavul, S., Siegel, D., \& Wright, M. (2015). New Financial Alternatives in Seeding Entrepreneurship: Microfinance, Crowdfunding, and Peer-to-Peer Innovations. Entrepreneurship Theory \& Practice, 39(1), 9-26.

Carli, F., \& Uras, B. (2017). Joint-liability with endogenously asymmetric group loan contracts. Journal of Development Economics, 127, 72-90.

Corbin, J., \& Strauss, A. (2008). Basics of qualitative research: Techniques and procedures for developing Grounded Theory. Los Angeles, CA: Sage.

Coriat, B., \& Guennif, S. (1998). Self-interest, trust and institutions. In E.H. Lorenz \& N. Lazaric, Trust and Economic Learning (pp. 48-63). Cheltenham: Elgar.

Corley, G. K., \& A. D. Gioia. (2004). Identity Ambiguity and Change in the Wake of a Corporate Spin-off. Administrative Science Quarterly, 49, 173-208.

Das, T. K., \& Teng, B-S. 1998. Between Trust and Control: Developing Confidence in Partner Cooperation in Alliances. The Academy of Management Review, 23(3), 491-512.

Denzin, N., \& Lincoln, Y. (2011). Introduction: The Discipline and Practice of Qualitative Research. In N. Denzin., \& Y. Lincoln, The Sage Handbook of Qualitative Research (pp. 1-20). Thousand Oaks, CA: Sage. 
Doney, P., \& J. Cannon. (1997). An examination of the nature of trust in buyer-seller relationships. Journal of Marketing, 61, 35-51.

Doney, P., J. Cannon., \& Mullen, M. (1998). Understanding the Influence of National Culture on the Development of Trust. Academy of Management Review, 23, 601-620.

Dowla, A. (2006). In credit we trust: Building social capital by Grameen Bank in Bangladesh. The Journal of Socio-Economics, 35, 102-122.

Elsner, W., \& Schwardt, H. (2015). From Emergent Cooperation to Contextual Trust, and to General Trust: Overlapping Meso-Sized Interaction Arenas and Cooperation Platforms as a Foundation of Pro-Social Behavior. Forum for Social Economics, 44(1), 69-86.

Guérin, I., \& Kumar, S. (2017). Market, Freedom and the Illusions of Microcredit. Patronage, Caste, Class and Patriarchy in Rural South India. The Journal of Development Studies, 53, 741-754.

Gulati, R. (1995). Does familiarity breed trust? The implications of repeated ties for contractual choice in alliances. The Academy of Management Journal, 38(1), 85-112.

Haldar, A., \& Stiglitz, J. (2016). Group Lending, Joint Liability, and Social Capital: Insights from the Indian Microfinance Crisis. Politics and Society, 44 (4), 459-497.

Hofstede, G. (1980). Culture's consequences. Beverly Hills, CA: Sage.

Hofstede, G. (1984). Culture's consequences: International differences in work related values. Beverly Hills, CA: Sage.

Johnson, S. (2004). Gender norms in financial markets: Evidence from Kenya. World Development, 32(8), 1355-1374.

Kale, S. H., \& J.W. Barnes. (1992). Understanding the domain of cross-national buyer-seller interactions. Journal of International Business Studies, 23(1), 101-132.

Kotir, J., \& Obeng-Odoom, F. (2009). Microfinance and rural household development: A Ghanaian perspective. Journal of Developing Societies, 25(1), 85-105.

Lascaux, A. (2015). Symposium on 'Trust'. Forum for Social Economics, 44(1), 46-47.

Lewicki, R.., \& Bunker. B. (1996). Developing and maintaining trust in work relationships. In R. Kramer \& T. Tyler, Trust in Organizations: Frontiers of Theory and Research, (pp. 114139). Thousand Oaks, CA: Sage Publication.

Lewis, J., \& Weigert, A. (1985). Trust as a Social Reality. Social Forces, 63, 967-985.

Lindskold, S. (1978). Trust development, the GRIT proposal and the effects of conciliatory acts on conflict and cooperation. Psychological Bulletin, 85, 772-793.

Marie, A. (Ed.). (1997). L'Afrique des individus [Africa of individuals]. Paris: Orstom. 
Milanov, H., Justo, R \& Bradley, S. (2015). Making the most of group relationships: The role of gender and boundary effects in microcredit groups. Journal of Business Venturing, 30, 822-838.

Mpofu, E. (1994). Exploring the Self-Concept in an African Culture. Journal of Genetic Psychology, 155 (3), 341-354.

Nooteboom, B. (2002). Trust, Forms, Foundations, Failures and Figures. Cheltenham: Elgar.

Ojong, N. (2018). Trust, cultural norms and financial institutions in rural communities: the case of Cameroon, Review of Social Economy, 76(1), 19-42.

Panda, D. (2016). Trust, social capital, and intermediation roles in microfinance and microenterprise development. VOLUNTAS: International Journal of Voluntary and Nonprofit Organizations, 27 (3), 1242-1265.

Pirttilä-Backman, A-M., Kassea, B., \& Ikonen, T. (2004). Cameroonian forms of collectivism and Individualism. Journal of Cross-Cultural Psychology, 34(4), 481-498.

Poppo, L., Zhou, K., \& Li, J. (2016). When can you trust 'trust'? Calculative trust, relational trust and supplier performance. Strategic Management Journal, 37, 724-741.

Pratt, M. (2009). From the Editors: For the Lack of a Boilerplate: Tips on Writing Up (and Reviewing) Qualitative Research. Academy of Management Journal, 52(5), 856-862.

Rempel, J., \& Holmes, J. (1986). How do I trust thee? Psychology Today, 20(2), 28-34.

Researchomatic. (2012). Global Economics, http://www.researchomatic.com/GlobalEconomics-116543.html Accessed 6 July 2017.

Rousseau, D., Sitkin, S., Burt, R., \& Camerer, C. (1998). Not so Different after All: A CrossDiscipline View of Trust. Academy of Management Review, 23 (3), 393-404.

Sanyal, P. (2015). Group-based Microcredit \& Emergent Inequality in Social Capital: Why Socio-religious Composition Matters. Qualitative Sociology, 38, 103-137.

Servet, J-M. (2015). La vraie révolution du microcrédit [Microcredit's real revolution]. Paris: Odile Jacob.

Servet, J.-M. (1997). Le Chapeau [The hat]. In P. Bernoux \& J.-M. Servet, La construction Social de la Confiance [The social construction of trust] (pp. 17-38). Paris: Collection Finance et Société.

Siwale, J., \& Okoye, N. (2017). Microfinance regulation and social sustainability of microfinance institutions: the case of Nigeria and Zambia. Annals of Public and Cooperative Economics, 88(4), 611-632.

Smallbone, D., Welter, F., \& Ateljevic, J. (2014). Entrepreneurship in emerging market economies: Contemporary issues and perspectives. International Small Business Journal, 32(2), 113-116. 
Sriram, M. (2005). Information asymmetry and trust: A framework for studying microfinance in India. Vikalpa, 30(4), 77-85.

Strub, P., \& Priest, T. (1976). Two patterns of establishing trust: The marijuana user. Sociological Focus, 9, 399-411.

Taylor, S.J. (1984). Introduction to Qualitative Research Methods. New York, NY: John Wiley.

Ueno, S., \& Sekaran, U. (1992). The influence of culture on budget control practices in the USA and Japan: An empirical study. Journal of International Business Studies, 23, 659674.

van Bastelaer, T., \& Leathers, H. (2006). Trust in Lending: Social Capital and Joint Liability Seed Loans in Southern Zambia. World Development, 34(10), 1788-1807.

Welter, F. (2012). All you need is trust? A critical review of the trust and entrepreneurship literature. International Small Business Journal, 30(3), 193-212.

Welter, F., \& Smallbone, D. (2006). Exploring the role of trust in entrepreneurial activity. Entrepreneurship Theory and Practice, 30, 465-475.

Williamson, O. (1993). Calculativeness, trust and economic organization. Journal of Law and Economics, 30, 131-145. 